\title{
CITOMETRIA DE FLUXO: HISTÓRICO, PRINCÍPIOS BÁSICOS E APLICAÇÕES EM PESQUISA
}

Karla Márcia da Silva Braga ${ }^{1}$, Vanessa de Sousa Cruz Pimenta ${ }^{2}$, Fernanda Almeida Rodrigues $^{3}$, Thais Poltronieri dos Santos ${ }^{4}$, Eugênio Gonçalves de Araújo ${ }^{5}$

1 Doutoranda do Programa de Pós-Graduação em Ciência Animal da Escola de Veterinária e Zootecnia da Universidade Federal de Goiás, Goiânia, Brasil (karla.braga@yahoo.com.br)

2 Pós-doutoranda, Laboratório Multiusuário de Cultivo Celular da Universidade Federal de Goiás, Goiânia, Brasil

3 Doutoranda do Programa de Pós-Graduação em Ciência Animal da Escola de Veterinária e Zootecnia da Universidade Federal de Goiás, Goiânia, Brasil

4 Graduanda em Medicina Veterinária da Escola de Veterinária e Zootecnia da Universidade Federal de Goiás, Goiânia, Brasil

5 Professor Doutor do Setor de Patologia Veterinária da Universidade Federal de Goiás, Goiânia, Brasil

Recebido em: 08/04/2016 - Aprovado em: 30/05/2016 - Publicado em: 20/06/2016 DOI: 10.18677/Enciclopedia_Biosfera_2016_027

\section{RESUMO}

A citometria de fluxo é uma poderosa ferramenta que possibilita realizar a separação, a contagem individual de células e detecção de biomarcadores proteicos. A partir de um feixe de laser incidente, é feita a medição da dispersão e da fluorescência do feixe de laser refletido pela da amostra celular. A dinâmica funcional de um citômetro é composta por cinco sistemas: fluido, óptico, eletrônico, de amplificação e computacional. O objetivo desse trabalho é apresentar uma visão geral do desenvolvimento histórico da citometria de fluxo, elucidar os princípios básicos da metodologia empregada e ressaltar a sua relevância nos estudos celulares inseridas na biologia molecular.

PALAVRAS-CHAVE: Célula, fluorocromos, granulometria.

\section{FLOW CYTOMETRY: HISTORY, BASIC PRINCIPLES AND RESEARCH APPLICATIONS}

\begin{abstract}
Flow cytometry is a powerful tool that enables cell sorting and counting, as well as cell protein biomarkers detection detecção de biomarcadores em proteínas. After a laser beam hits the sample, the light that scatters and the fluorescence emission from the cell are measured. Five systems build up the functional dynamics of a cytometer: fluid, optic, electronic, amplification e computational. The purpose of this work is to present a general view of flow cytometry historical development, unveil the basic methodological principals and emphasize the importance of this technique in cell studies in the molecular biology field.
\end{abstract}

KEYWORDS: Cell, fluorochromes, granulometry. 


\section{INTRODUÇÃO}

A identificação de componentes microscópicos dos seres vivos tem desafiado os cientistas desde que Robert Hooke introduziu o conceito de célula no século XVII. O aperfeiçoamento dos microscópios permitiu descortinar, parafraseando Aldous Huxley um "admirável mundo novo". Porém, somente com a introdução das técnicas de detecção microscópica com o uso de anticorpos tornouse possível a identificação de componentes celulares como as proteínas. O desenvolvimento de novas tecnologias como a citometria de fluxo permitiu identificar e caracterizar as propriedades físico-químicas de células individuais dentro de populações homogêneas ou heterogêneas de micropartículas presentes em seres vivos. Essa tecnologia, por suas relevantes contribuições em pesquisas científicas tem despertado grande interesse em áreas da imunologia molecular e da clínica, como apoio para o diagnóstico e prognóstico da enfermidade (BERTHO, 2015).

A citometria de fluxo (FC) é uma técnica bem estabelecida pela utilização de laser óptico, tem como função realizar a separação, a contagem individual de células e detecção de biomarcadores em proteínas. A técnica por meio de um feixe de laser incidente faz a medição da dispersão e da fluorescência do feixe de laser refletido, a partir da amostra celular. Empregada em estudos de células em fluxo e por possuir amplas aplicações é denominada como citometria de fluxo multiparamétrica (FCM) (TEVA et al., 2009).

A versão mais moderna da FC é chamada de FACS (separador celular ativado por fluorescência) é resultante do aprimoramento tecnológico, que se utiliza da automação das análises e faz a diferenciação celular pelo emprego prévio de anticorpos fluorescentes. Assim, fornece informações rápidas e precisas com a identificação de inúmeras características intrínsecas ou extrínsecas contidas nas células, e reconhecer com precisão o tamanho, e a granulosidade, por meio da leitura da intensidade da fluorescência refletida em células previamente marcadas com anticorpos monoclonais fluorescentes (O'DONNELL et al., 2013).

Esta revisão tem por objetivo apresentar uma visão geral do desenvolvimento histórico da FC, elucidar os princípios básicos da metodologia empregada e ressaltar, sobretudo, a relevância da citometria de fluxo com valiosas aplicações nos estudos celulares inseridos na biologia molecular e da medicina.

\section{CITOMETRIA DE FLUXO A PARTIR DO ADVENTO DA MICROSCOPIA ÓPTICA}

A integridade da vida é resguardada pela manutenção da homeostase sanguínea, que assegura a subsistência para a sobrevivência humana. $\mathrm{Na}$ antiguidade, o fluido sanguíneo com propriedades até então desconhecidas, foi revelado como o cerne da vida. O advento da citometria de fluxo (FC) pode ser contextualizado inicialmente pelo desenvolvimento do primeiro microscópio óptico no início do século XVII, no ano de 1674, pelo inventor holandês Antony van Leeuwenhoek, que promoveu uma verdadeira revolução na ciência médica. $O$ microscópio era um instrumento rudimentar, de pequenas dimensões, composto por um suporte da amostra, um tradutor da amostra, um botão de foco, por única lente de vidro. Contudo, o instrumento possibilitou a ampliação de aproximadamente 300 vezes, com o qual observou-se pequenas estruturas micrométricas, denominadas células, de resolução variável entre um a dois micrômetros, com moderada nitidez (MURMANN, 2007).

Leeuwenhoek, notável observador motivado pelo interesse em reconhecer a existência de novos seres vivos, com o advento da microscopia óptica 
tornou possível à visualização individual de componentes sanguíneos. Desse modo, no ano de 1674, determinou-se que o sangue é constituído por pequenos glóbulos vermelhos, descreveu-os com exatidão e determinou o tamanho celular. Em 1677, durante suas pesquisas, identificou e descreveu a presença de espermatozoides no sêmen humano. Realizou estudos com plantas, observou tecidos musculares, reconheceu a existência de microrganismos tais como protozoários e bactérias, discriminando estas em três tipos: cocos, bacilos e espirilos. Leeuwenhoek por suas primorosas contribuições à ciência e a humanidade é reconhecido como o benemérito criador da microbiologia (ALTMAN, 2012).

Posteriormente, Robert Hooke aperfeiçoou o microscópio de Leeuwenhoek com a criação do primeiro microscópio composto por duas lentes, que permitiu melhor ampliação da imagem. Embora os estudos alcançados por Leeuwenhoek e Hooke tenham conduzido às descobertas celulares, a célula somente foi identificada como unidade essencial da vida no ano de 1839, no texto que se conhece escrito pelo botânico Matthias Jacob Schleiden e pelo zoólogo e fisiologista Theodor Schwann (ALTMAN, 2012).

William Henry Perkin descobriu em 1856 a anilina roxa, o primeiro corante sintético. Em 1870, Paul Ehrlich usou o corante em suas amostras, distinguiu os tipos de células brancas e relatou que a quantidade celular é variável conforme o estado de higidez ou enfermidade. A partir da descoberta celular foi acrescido ao microscópio, o sistema de luz, oculares, lentes objetivas, que conferiram melhor qualidade óptica mediante correções das distorções nas imagens. Malanchowski e Romanowsky em 1891, com o uso de corantes e fluorocromos, investigou enfermidades como a malária a partir da análise clínica das células. Diagnósticos e métodos preventivos foram determinados pela contagem individual da concentração celular, uma técnica laboriosa, demorada, de baixo custo, porém passível de erros. Esforços convergiram para a evolução de métodos automatizados que permitissem quantificar e qualificar as células com maior rapidez e precisão. Diante dessa necessidade, surgiu a citometria para a mediação celular via microscópio, e posteriormente a FC (MURMANN, 2007;GREEN et al., 2015).

\section{HISTÓRICO}

A citometria de fluxo foi desenvolvida primeiramente em 1934 por Andrew Moldavan, que desenvolveu um sistema em que células coradas dentro de um tubo capilar sob a luz do microscópio óptico passavam por um detector fotoelétrico, e procedia a contagem celular conforme a incidência da luz. Em 1947, cenário marcado pelo período pós-Segunda Guerra Mundial, Gucker JR desenvolveu um projeto para identificação individual de partículas para testar filtros de ar contra esporos usados em armas biológicas ou bactérias. Com sucesso, Gucker JR inventou em 1948 um dispositivo fotoeletrônico que contava partículas de DOP dioctil-ftalato, um polímero com 0,6 $\mu \mathrm{m}$ de diâmetro para ser adaptado em outras substâncias ou microrganismos como bactérias. $O$ método se baseava na passagem de partículas suspensas em ar através de um capilar que detectava partícula fotossensitiva por espalhamento de luz (BERTHO, 2015).

Em 1949, Wallace Coulter criou um contador fundamentado no diferencial da impedância elétrica celular em solução salina, que permitia avaliar o tamanho de células do sangue; o aparelho foi patenteado como contador Coulter. Em 1953, Crosland e Taylor, baseados no princípio de Gucker Jr., desenvolveram uma câmara em que amostras foram colocadas no centro de um fluxo de revestimento, pelo qual um capilar de maior diâmetro era passado na parte central desse sistema, o que 
evitava o entupimento do capilar e possibilitava melhor foco das amostras pela fonte de luz. Essa câmara tornou-se a referência para as utilizadas atualmente. Katmentsky criou em 1965, o RCS (Espectrofotômetro Celular Rápido), que usou a espectrofotometria para mensurar o tamanho celular e quantificar o DNA, inserindo a análise multiparamétrica de luz dispersada, bem como utilizando pioneiramente histogramas biparamétricos. Com o emprego de substâncias fluorescentes, alcançou um menor sinal que os corantes e absorção (BERTHO, 2015).

Em 1965, Fulwyler registrou o processo de separação (sorting) eletrostático, com auxílio tecnológico de impressora jato de tinta. Van Dilla, utilizando a câmara de Crosland e Taylor entre 1967 e 1969, apresentaram o primeiro citômetro de fluxo de formato ortogonal e mostraram a associação entre ploidia e a proporção de fluorescência na quantificação de DNA, possibilitando identificar as fases do ciclo celular por histogramas. No ano de 1972, Bonner et. al., apresentaram - FACS (Separador Celular Ativado por Fluorescência), que possibilitou que células fossem sinalizadas com fluorocromos, classificadas eletrostaticamente, e ao serem atingidas por feixe luminoso de laser, mensuraram a fluorescência e o espalhamento frontal da célula, obtendo melhor resultado entre sinal e ruído. Nas décadas de 1960 e início dos anos 1970 houve relevantes desenvolvimentos e aprimoramentos tecnológicos na FC, todavia, escassos relatos descreveram novas aplicações biológicas (BERTHO, 2015).

O emprego da FC na biomedicina foi progressivo a partir de 1975. Reinherz, em 1975, reconheceu subpopulações de células em função dos antígenos de superfície mediante o uso de anticorpos monoclonais. Fases do ciclo celular foram observadas com a técnica da bromodeoxiuridina (BrdU) e anticorpos testados por Gratzner, 1975. Estudo sobre o cariótipo foi realizado por Gray, em 1975. Loken, em 1977, usou o feixe de um único laser para mensurar dois antígenos celulares, com compensação eletrônica de sinal entre a tetrametilrodamina (RD) e o isotiocianato de fluoresceína (FITC). Condições fisiológicas foram medidas pela técnica citofluorimétrica entre os anos de 1979 a 1980, como por exemplo, por Visser, pH intracelular, e o estado redox por Thorell. Em 1982, foi utilizado a ficobiliproteínas como fluorocromos. Darzynkiewicz e Traganos usaram a coloração fluorocromática laranja de acridina em DNA e RNA, 1982, entre outros (BERTHO, 2015).

O desenvolvimento de tecnologia em FC tem acompanhado de perto a tecnologia laser, a fonte de luz para excitar sondas fluorescentes, como uma ferramenta de investigação e diagnóstico, que pode ser empregada em diversas áreas de interesse na ciência. Atualmente, a FC é o modelo mais aplicado para análise celular, como por exemplo, em pesquisas clínicas laboratoriais no controle de células CD4 em pacientes portadores do vírus HIV, na investigação de doenças hematológicas com características de malignidade, bem como desenvolvimento de fármacos (TEVA et al., 2009; TELFORD, 2015; DU et al. 2015).

\section{TÉCNICA}

A FC é uma técnica baseada no emprego de laser óptico amplamente

utilizado para triagem, contagem individual de células e detecção de biomarcadores em proteínas. A técnica por meio de um feixe de laser incidente faz a medição da dispersão e da fluorescência do feixe de laser refletido, a partir da amostra celular. Empregada em estudos de células em fluxo e por possuir amplas aplicações é denominada como citometria de fluxo multiparamétrica (FCM). A FCM realiza a rápida identificação de células no instante que estas passam 
através de um aparelho de detecção eletrônica em uma corrente líquida. Após a separação individual celular é feita a análise, contagem, e qualificação das micropartículas suspensas em fluxo, em meio líquido. Desse modo, realiza com rapidez a identificação de inúmeras características biológicas contidas nas células como: os ácidos nucleicos, receptores de superfície, epítopos de proteínas, a síntese de proteínas, de citocinas, e concentração de íons, ao mesmo tempo dentro de uma célula única. A vantagem desta tecnologia é a capacidade para a medição simultânea de vários parâmetros. Por meio dessas múltiplas informações resultam em uma compreensão minuciosa sobre a linhagem, estado de ativação ou a patologia celular (BENDALL et al., 2012; FANG \& RAMASAMY , 2015).

A realização da FC pelo aperfeiçoado modelo FACS (Separador de Célula Ativado por Fluorescência) (Figura 1) tem sido por muitos pesquisadores o instrumento de automação mais utilizado para a investigação celular e seleção das amostras celulares previamente coradas com anticorpos fluorescentes (TEVA et al., 2009).

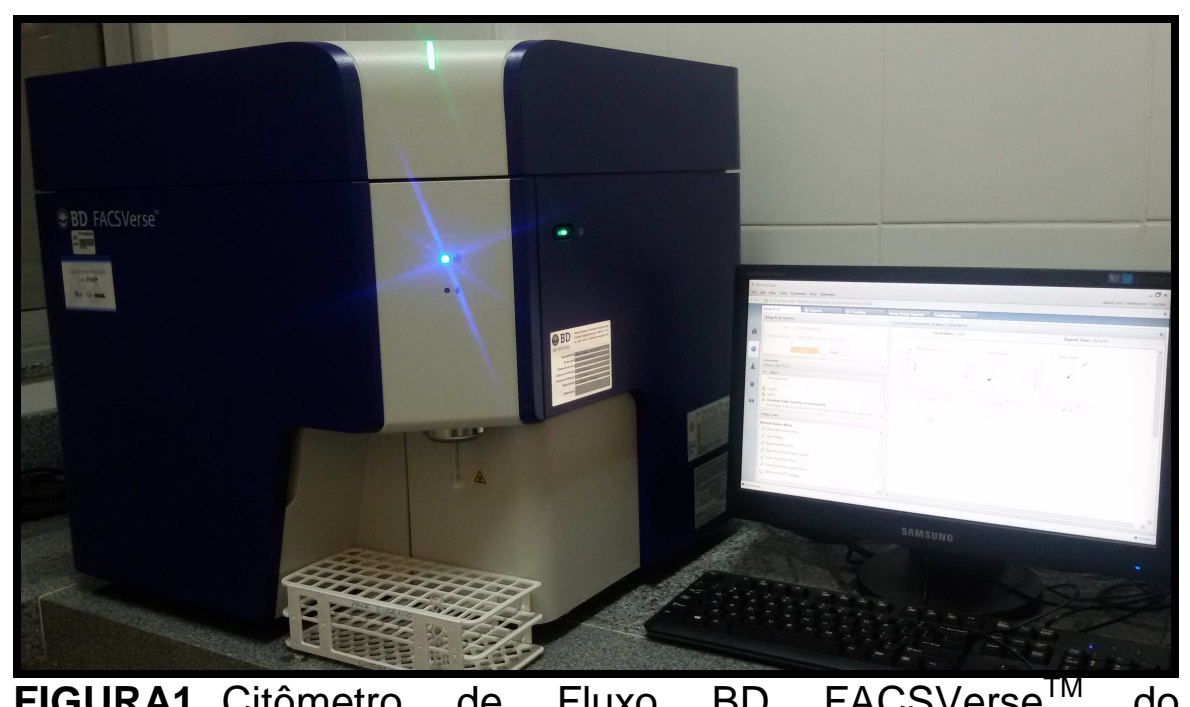

Laboratório Multiusuário de Cultivo Celular do Programa de Pós-Graduação em Ciência Animal da Universidade Federal de Goiás. Fonte: Arquivo Pessoal

O princípio de funcionamento do FACS utiliza feixe de laser e um identificador de luz para a contagem individual das células íntegras que se encontram em suspensão. As prováveis medições das propriedades físicas e/ou químicas da célula ocorrem por captação que emprega um sistema óticoeletrônico que aponta o modo como a célula ou partícula faz a dispersão da luz do laser refletido, irradiando a fluorescência. Assim, as propriedades celulares mais analisadas dentro do sistema de FACS compreendem o complexo mecanismo interno das micropartículas, o tamanho, granulosidade e a intensidade da fluorescência (Figura 2) (TEVA et al., 2009).

Ainda que a FC seja utilizada rotineiramente pela grande versatilidade em termos de parâmetros celulares identificados e sensibilidade, novas tecnologias vêm sendo utilizadas para aperfeiçoar esse método. A mais importante é a citometria de massa, na qual as células também são marcadas com anticorpos 
conjugados. No entanto, diferente da FC onde os anticorpos são conjugados a fluorocromos, na citometria de massa são conjugados a isótopos de metais raros, que são posteriormente detectados por um espectrômetro de massa conjugado ao citômetro. Como vantagem principal, a capacidade multiparamétrica da citometria de massa é maior que a de fluxo, com 44 parâmetros mensuráveis já relatados e perspectiva de análise simultânea de 100 parâmetros em um futuro próximo. A maior desvantagem, possivelmente, é que as células são destruídas durante a análise, impedindo 0 isolamento para utilização em outros experimentos (HERDERSCHEE et al., 2015).

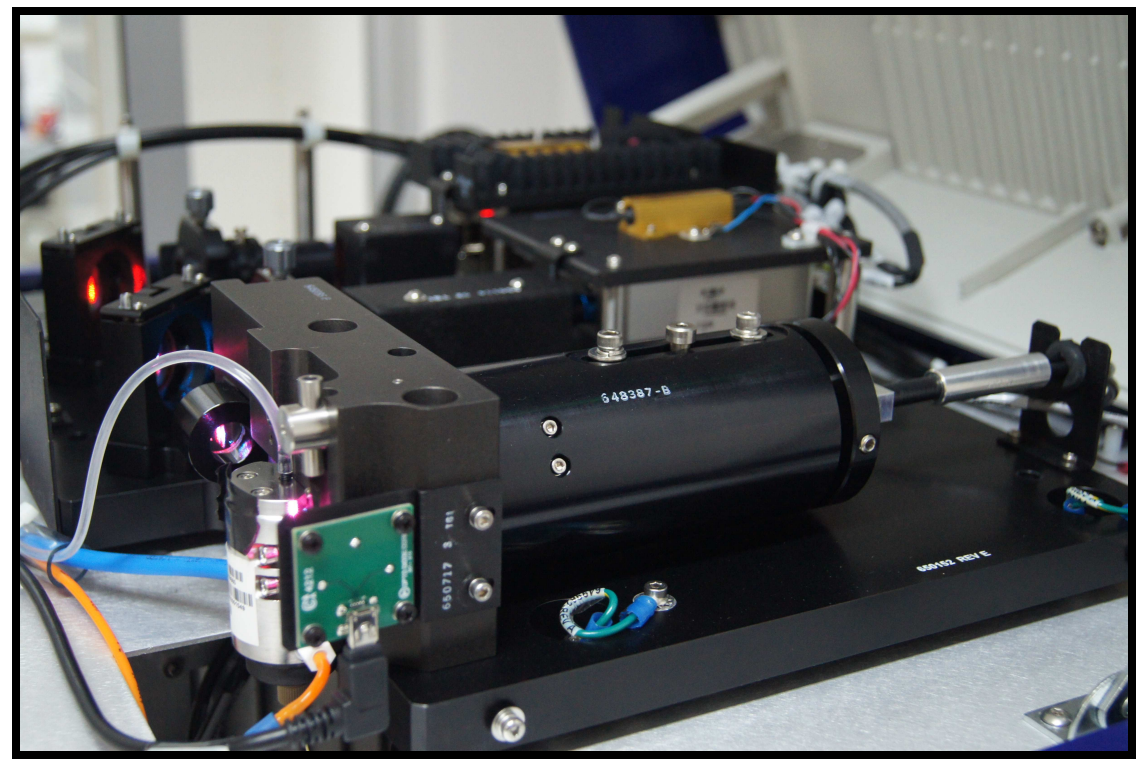

FIGURA 2. Sistema ótico-eletrônico de dispersão de luz do laser refletido, do citômetro de fluxo BD FACSVerse ${ }^{\mathrm{TM}}$ do Laboratório Multiusuário de Cultivo Celular do Programa de Pós-Graduação em Ciência Animal da Universidade Federal de Goiás, que irradia a fluorescência.

Fonte: Arquivo Pessoal.

\section{PRINCÍPIOS BÁSICOS}

A FC mensura parâmetros em células que fluem através de um sistema de análise. O processo se inicia com a seleção de anticorpos, marcados com fluorocromos e específicos para o antígeno celular que permite caracterizar a população das células de interesse. Após o processamento da amostra, obtida a partir de fluidos ou processamento de tecidos sólidos, uma suspensão de células é introduzida no aparelho, fluindo em direção a um laser posicionado no caminho das células. Como o fluxo das células é laminar e o diâmetro do tubo se afunila, as células são forçadas a passar em fila única pela luz emitida pelo laser. $O$ fluorocromo ligado ao anticorpo absorve a energia do laser e rapidamente emite essa energia em forma de luz, em comprimentos de ondas específicos de acordo com o fluorocromo empregado. A luz emitida é captada por um sistema óptico que é sensível a diferentes comprimentos de onda, permitindo que um ou mais marcadores sejam lidos ao mesmo tempo, transferindo essas informações para um computador acoplado ao sistema. Programas especializados podem, então, representar 
graficamente, em formatos uni, bi ou tridimensional, a distribuição de populações celulares marcadas (FANG \& RAMASAMY, 2015).

A dinâmica funcional dos citômetros de fluxo é composta essencialmente por cinco sistemas. A primeira é o sistema fluído, espécie de câmara pelo qual as células são introduzidas e alinhadas uma a uma por diferença de pressão, onde serão impactadas pela luz do laser. O Sistema Óptico é parte que abriga a fonte emissora de luz do laser, lâmpadas de xênon ou mercúrio, potentes lasers de argônio, ou lasers com baixo poder, além dos lasers de diodo que são, azul, verde, vermelho e violeta. (Figura 3). Detectores são ativados localmente por onde o fluxo incide através do feixe luminoso do laser. A luz é dispersa na linha do feixe retilíneo denominado espalhamento frontal (Forward Scatter - FSC) equivalente ao volume celular, e também por feixes perpendiculares ou espalhamento lateral (Side Scatter SSC) sujeito à complexidade interna da partícula como exemplo o formato nuclear, a quantidade e tipo dos grânulos citoplasmáticos e deformidade da membrana, além destes, de um ou mais detectores fluorescentes (TEVA et al., 2009).

Um sistema eletrônico capta os sinais ópticos e os converte em sinais eletrônicos, intermediado do sistema analógico para o sistema digital, com a reprodução do FSC, SSC e sinais fluorescentes. Assim que uma célula ou partícula passa através da luz do laser, a luz espalhada lateralmente e os sinais fluorescentes são direcionados aos tubos fotomultiplicadores (photomultiplier tubes - PMTs), enquanto um fotodiodo de silicone recolhe os sinais espalhados frontalmente. $O$ sistema de amplificação é responsável por codificar e processar os dados recebidos no formato de escala logarítmica ou linear. O sistema computacional via software executa as análises, processa os sinais e emite os resultados obtidos (TEVA et al., 2009).

Estão disponíveis para a comercialização dois tipos de citômetros de fluxo, o citômetro de bancada (banch-up flow cytometers) e o separador de células (cell sorters). O citômetro de bancada é normalmente equipado com laser de argônio de baixa intensidade é, portanto, o mais usado ou laser He-Ne, é refrigerado a ar, possui até quatro cores. O cell sorter é uma versão mais completa e complexa, composto por vários componentes eletrônicos, é dotado de laser de alta potência, por isso necessita de refrigeração à água e possuem até 11 cores, dentro de uma suspensão heterogênea (sorting) faz a separação física das células. Mediante o grau de complexidade do equipamento requer o manuseio especializado, são de alto custo, e geralmente destinados a grandes centros de pesquisas por ter amplas possibilidades de aplicações (BERTHO, 2015).

Em geral, os citômetros de fluxo são compostos por dois ou mais tipos de lasers, que ampliam a capacidade de medições multiparamétricas. A luz monocromática, estável e de alta potência, é a mais utilizada em citômetros de fluxo, os lasers podem emitir feixes de luz fixa ou podem ser sintonizáveis, por ser de alta potência são refrigerados à água, enquanto que os de baixo poder são refrigerados a ar. O laser empregado com maior frequência na FC é o laser íons de argônio com emissão de 488nm, que permite maior excitação em fluorocromos, como a Anexina V, brometo de propídeo, FITC, PE, PI, PerCP, \&-AAD, laranja de acridina, entre outros (BERTHO, 2015). 


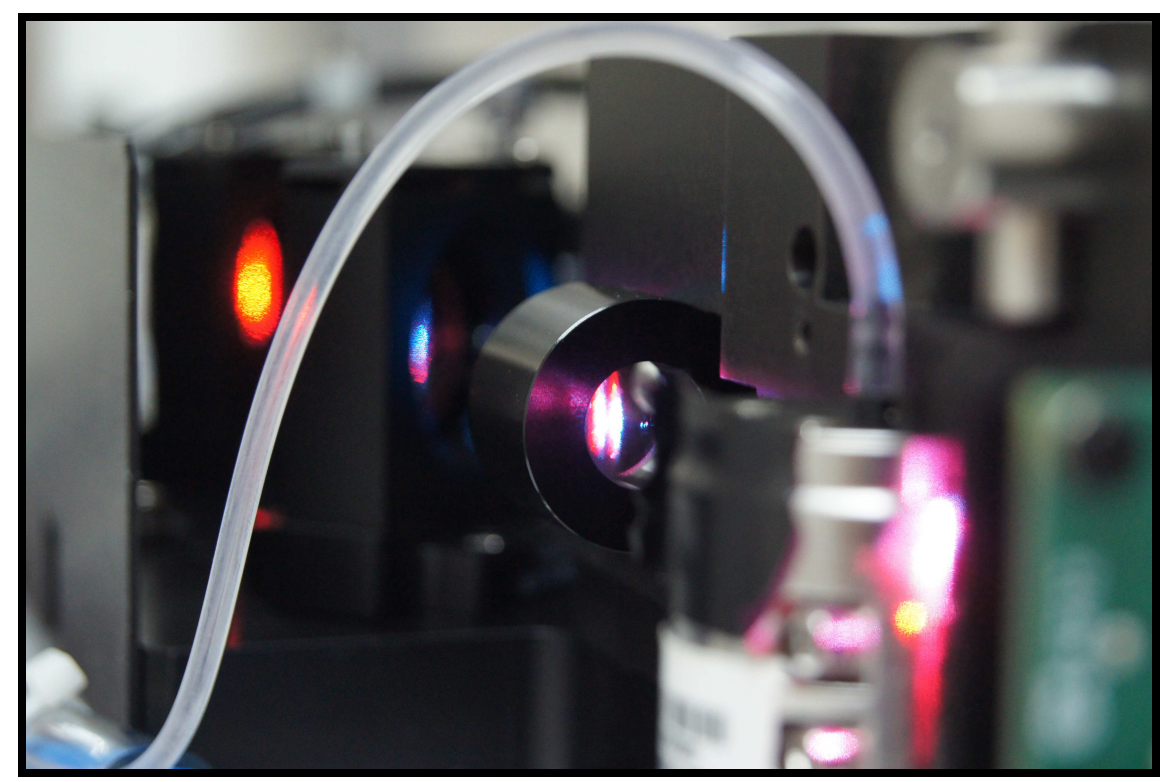

FIGURA 3. Sistema óptico do Citômetro de Fluxo BD FACSVerse ${ }^{T M}$ do Laboratório Multiusuário de Cultivo Celular do Programa de Pós-Graduação em Ciência Animal da Universidade Federal de Goiás, parte que abriga a fonte emissora do laser.

Fonte: Arquivo Pessoal

\section{PREPARAÇÃO DA AMOSTRA E FLUOROCROMOS}

Para utilizar a FC como ferramenta de estudo, as amostras devem estar em uma suspensão. A amostra pode ser de sangue periférico, de cultivo celular, de medula óssea, de tecido, ou de líquor; em todos os casos, as células devem ser dissociadas e de forma a evitar a formação de grumos na suspensão. Amostras de tecidos sólidos como fígado ou fragmentos de tumores também podem ser estudados, desde que as células sejam separadas por métodos mecânicos ou enzimáticos. Os métodos mecânicos envolvem picagem e moagem, seguidas de várias passagens por agulhas finas ou sonicação. Os métodos enzimáticos podem permitir, além da separação das células, a permeabilização da membrana celular, condição essencial para a passagem dos fluorocromos no estudo de componentes intracelulares (RAHMAN, 2015).

A base para os protocolos citofluorimétricos é a identificação de moléculas na superfície ou no interior das células (imunofenotipagem) acontece por meio da utilização de anticorpos monoclonais conjugados à fluorocromos ou substâncias fluorescentes, ambos capazes de emitir cor (FERRAZ, 2015).

Os fluorocromos são, essencialmente, corantes que absorvem energia luminosa a um determinado comprimento de onda e emitem de volta essa mesma energia em comprimento de onda ainda maior. Esses processos são denominados excitação e emissão, respectivamente. O processo de emissão ocorre de forma extremamente rápida, em nanosegundos, sendo conhecido como fluorescência (RAHMAN, 2015).

A maioria dos fluorocromos é excitada por um laser argônio (comprimento de onda de $488 \mathrm{~nm}$ ). Alguns fluorocromos são excitados por outro comprimento de onda, e para isto, é necessário que os citômetros sejam 
equipados com mais de um laser. Alguns lasers comuns neste tipo de equipamento são o ultravioleta $(355 \mathrm{~nm})$, violeta-azul $(405 \mathrm{~nm})$ e hélio-neônio (633nm) (FERRAZ, 2015).

A luz é uma forma de energia eletromagnética que se propaga em ondas. Tais ondas possuem frequência e comprimento, sendo que este determina a cor da luz. A luz que pode ser visualizada pelo olho humano situa-se em um estreito espectro (380-700 $\mathrm{nm}$ ) entre o ultravioleta (UV) e a radiação infravermelha (IV). Das cores visíveis (vermelho, laranja, amarelo, verde, azul e vermelho) a luz vermelha possui maior comprimento de onda (energia mais baixa), enquanto o violeta possui o menor comprimento (e maior nível de energia) (RAHMAN, 2015).

Os fluorocromos oferecem um método sensível para obter informação acerca da estrutura, função e vitalidade das células. Existem dois modos de uso: (1) ligação covalente do fluorocromo a moléculas que se unem especificamente a componentes celulares, e (2) fluorocromos que variam suas características em função do microambiente que os cerca. Os primeiros reagem com proteínas, lipídeos ou outras moléculas biológicas, permitindo sua marcação de forma seletiva; em geral, são utilizados cromóforos dos grupos isotiocianato, clorotrirzinil, e ésteres de succinimida por sua capacidade de ligação, sendo a fluoresceína na forma de isotiocianato (FITC) o cromóforo mais utilizado. Já no caso do segundo grupo, os mais importantes são os marcadores de DNA e RNA, como o DAPI (se liga na sequência de bases $A-T-)$, e o iodeto de propídeo (PI) que se excita com um laser de $488 \mathrm{~nm}$ (BERTHO, 2015).

Os citômetros de fluxo modernos possuem a capacidade de analisar 20 ou mais sondas fluorescentes simultaneamente, o que requer capacidade de captar emissões em comprimentos de onda múltiplos. Uma estratégia para aumentar o número de comprimentos de onda detectáveis é o desenvolvimento de sondas fluorescentes que podem ser excitáveis por lasers próximos aos limites do espectro visível, mais próximo das extremidades do ultravioleta ou do vermelho. A região próxima ao vermelho (vermelho de alto comprimento de onda) representa uma das últimas fronteiras analisáveis por citometria de fluxo (TELFORD, 2015).

Os fluorocromos são geralmente acoplados a anticorpos com afinidade por determinada estrutura química das células e biologicamente significativas, as quais podem caracterizar um tipo celular, um evento bioquímico ou um tipo de resposta imunológica. O processo se inicia com a seleção de anticorpos marcados com os fluorocromos, frequentemente específicos para os marcadores de superfície celulares utilizados para caracterizar as populações celulares de interesse. Esses marcadores são geralmente glicoproteínas denominadas conglomerados de diferenciação (cluster of differentiation - CD) e permitem diferenciar subpopulações celulares; por exemplo, linfócitos $\mathrm{T}$ citotóxicos são positivos para CD3 e CD8 (JAHAN-TIGH et al., 2012).

\section{INTERPRETAÇÃO DOS DADOS}

Além dos dados obtidos por fluorescência, as informações de espalhamento frontal (FSC) e espalhamento lateral (SSC) podem ser obtidas com base no ângulo dos feixes de luz emitidos pela célula analisada. A FSC se espalha em um ângulo pequeno e é detectada por um sensor no lado oposto à fonte do laser azul de 488- nm (Figura 2). O FSC origina informações relacionadas ao tamanho da célula. Já o SSC é obtido a partir da luz que se espalha lateralmente, a um ângulo de $90^{\circ}$ da célula, fornecendo informações sobre a qu antidade e densidade dos grânulos da célula, o que poderia ser útil, por exemplo, para distinguir linfócitos de 
granulócitos. Os dados quantitativos do espalhamento das células são plotados na forma de gráficos de tal sorte que o eixo $X$ corresponda à intensidade de FSC e o eixo $Y$ à de SSC (Figura 4). Os eixos dos gráficos são nomeados de acordo com o fluorocromo e, se for o caso, o antígeno a ele ligado, como por exemplo, FITC-CD3 para células positivas para CD3 marcadas com FITC. As células positivas para ambos os marcadores localizam-se no quadrante superior direito, enquanto as negativas para ambos no quadrante inferior esquerdo (Figura 4) (RAHMAN, 2015).

Avançados recursos tecnológicos aliados à possibilidade de medição simultânea de um grande número de parâmetros, a FC tem sido atualmente o método de escolha para análises celulares, avaliações de frequências individuais ou para verificar a expressão de uma molécula específica dentro de populações homogêneas ou heterogêneas. Diante de uma diversidade de informações fornecidas pelas hipóteses testadas, os dados poderão ser interpretados pelo processo manual de gating. O "gating" é princípio básico para análise da FC no qual realiza o refinamento e identificação sequencial das populações de células em pesquisa, com a utilização de marcadores moleculares que ao serem atingidos por um espectro são ativados pela fluorescência. De acordo com a expressão desses marcadores as células de interesse são identificadas (gated), contudo essa identificação manual pode ser trabalhosa, porém, recentemente foram desenvolvidos softwares que fazem o processo de seleção das células de interesse de forma automática (BACHER et al., 2013; VERSCHOOR et al., 2015).

\section{APLICAÇÕES DA CITOMETRIA DE FLUXO EM PESQUISA}

A FC é uma técnica bastante versátil, relevante em investigações da biologia e da medicina, que pode ser aplicada em diversas situações em que seja necessária a caracterização de populações celulares. Como exemplos, podem ser citadas pesquisas em hematologia, oncologia, transplantes de órgãos, desenvolvimentos de vacinas, alterações plaquetárias, análise de respostas orgânicas a infecções por bactérias ou fungos, e em desenvolvimentos de fármacos a partir de extrato de plantas. É importante ressaltar que, em pesquisas que visem descobrir ou interferir em vias de transdução de sinal de resposta imune e/ou inflamatória, a única ferramenta que fornece a necessária sensibilidade e especificidade para monitorar subpopulações celulares é a FC (DU et al. 2015).

A técnica de FCM é largamente aplicada para realização de testes de função plaquetária que sugerem o diagnóstico de síndrome de Bernard-Soulier ou trombastenia de Glanzmann. Desta forma, a FCM quantifica a densidade correspondente do receptor de glicoproteína de membrana (GPlb-IX-V, allbb3), como para investigar e confirmar esses diagnósticos. A FCM pode ser usada, por exemplo, na identificação de alterações quantitativas de receptores para o colágeno (GPVI, A2B1) ou trombina (PAR-1) e para medir as respostas induzidas por agonistas de plaquetas, incluindo a exposição de fosfolípidos aniônicos (HARRISON et al., 2013; ISRAEL, 2015).

Em recente estudo hematológico, utilizou-se a citometria de fluxo a partir de amostra do sangue periférico para pesquisas de células progenitoras hematopoiéticas e pró-angiogênicas (PACs), visto que estas são constituintes de uma população de células específicas da medula óssea. Os estudos foram conduzidos pela evidência emergente de que esta subpopulação de células progenitoras hematopoiéticas desempenha um papel crítico na saúde e doença vascular. A FC foi utilizada para a caracterização individual dessas células com base em marcadores de superfície como o CD34 e CD 133 para expressão de células 
progenitoras e o VEGFR2 como marcador angiogênico. Considerando a importância da detecção e isolamento de PACs em diferentes áreas de pesquisa da doença, contudo, não há outra opção para caracterizar estas células. Dessa forma, a citometria de fluxo tem sido uma ferramenta essencial na identificação e acompanhamento destas células na medula óssea e no sangue periférico. Com um protocolo apropriado, estas células podem ser identificadas e ainda avaliadas para a expressão de marcadores da doença específica. A FC desempenhou importante função para compreensão dos estudos biológicos dessas células e bem como seu papel na fisiopatologia das desordens sanguíneas humanas (ROSE et al., 2015).

A FC é reconhecida como uma técnica bem estabelecida em pesquisas sobre transplantes, no reconhecimento de reação cruzada em pré-transplante e no monitoramento de reconstituição imunológica após o transplante de células-tronco hematopoiéticas. A FCM detalha os elementos do sistema imunitário, a sua função e interação e reagentes recém-desenvolvidos com base em análises multiparamétrica necessárias principalmente no cenário pós-transplante. Foi discutido o impacto da FC no controle de reações imunes, no acompanhamento de infecções oportunistas e rejeição do enxerto, assim como, na aferição da imunossupressão no contexto dos transplantes de órgãos sólidos. Entretanto a citometria de fluxo é uma técnica de suma importância que oferece informações valiosas sobre o estado imunológico de um destinatário a transplante, atua no acompanhamento da função imune após o transplante de órgão sólido, na avaliação da saúde do enxerto e do receptor. Ainda que a citometria de fluxo seja uma técnica bem estabelecida em transplantes, mas que deve ser validada para ser clinicamente aplicável como um padrão nos parâmetros de controle de qualidade dos enxertos (MANGUIRE et al., 2014).

A identificação de sítios (antígenos) para o desenvolvimento de vacinas tem sido realizada com o emprego da FC. A aplicação da técnica na quantificação de vírus para o desenvolvimento de vacinas para gripe é um grande desafio, devido ao tamanho da partícula viral ser de difícil detecção, proporcionalmente pela não identificação do genoma viral, o que não favorece a utilização de corantes nucleicos fluorescentes. O desenvolvimento de novos citômetros de fluxo equipados com detectores de FSC mais sensíveis tem possibilitado a identificação mais eficiente de partículas menores como, por exemplo, do vírus da gripe e em casos de HIV (MANCEUR et al., 2015).

Em meio às alternativas desenvolvidas para aperfeiçoar a definição de padrões de susceptibilidade de drogas e/ou de automação, a FACS emergiu como um recurso primordial para investigar a vulnerabilidade antimicrobiana de diferentes microrganismos, incluindo fungos. É uma importante tecnologia destinada a ampliar e melhorar a capacidade de laboratórios de microbiologia clínica para gerar resultados rápidos e confiáveis. Por meio da FC, é possível compreender os mecanismos celulares e moleculares que controlam a diferenciação celular em bactérias, as respostas fisiológicas distintas em bactérias, e também verificar respostas aos antibióticos e outros produtos químicos citotóxicos. Pelo processo automatizado da FC é possível avaliar as alterações funcionais e metabólicas dos microrganismos bacterianos, bem como identificar genes expressos especificamente em determinadas condições nas estruturas celulares. Estas análises podem ser obtidas a partir de amostras de cultivo celular de bactérias, com obtenção rápida e precisa dos resultados da avaliação individual celular. A FC, aliada a uma nova geração de sondas repórter celulares, tornou esta técnica adequada e indispensável para a identificação e quantificação de células presentes em subpopulações para 
análises de respostas fisiológicas em bactérias (AMBRIZ-AVIÑA et al., 2014; POSTERARO \& SANGUINETTI , 2014).

Abordagens recentes sinalizam que os métodos de FC são utilizados para avaliar a estabilidade da amostra utilizada durante o desenvolvimento de fármacos, ressaltando sua importância em todas as fases do desenvolvimento desse processo. Os métodos requerem avaliação da estabilidade adequada da amostra, para garantir a confiabilidade dos resultados obtidos. Alguns fatores exercem influência na estabilidade das amostras para ensaios de FC, como por exemplo, as condições pós-coleta e de processamento da amostra, temperatura, e transporte, o formato de ensaio, a escolha do anticoagulante ou estabilização célula reagente. Todavia, é necessária a utilização de uma instalação central para processamento, avaliação da estabilidade da amostra. Como exemplos, podem ser citadas análises de drogas alvo e farmacodinâmica em estudos pré-clínicos e clínicos, bem como a determinação de elegibilidade do paciente, estratificação para ensaios clínicos e avaliação final dos estudos de interesse. Sendo assim, a FC torna-se um instrumento muito útil em todas as fases do desenvolvimento de fármacos (BROWN et al., 2015).

A análise citométrica de fluxo do ciclo celular de células tumorais também foi aplicada para examinar a agressividade dos meningiomas, pois este método possui maior sensibilidade nas informações geradas, e melhor precisão sobre a taxa de proliferação de células de tumor do que os dados fornecidos pela histologia tradicional. Os meningiomas são o tipo mais comum de tumor do sistema nervoso central, e responsáveis por até $30 \%$ de todos os tumores intracranianos primários. O desenvolvimento tumoral tem origem nas meninges da medula espinhal e do cérebro. Contudo, esses tumores são histologicamente classificados como benignos e na maioria dos casos pode ser procedido à ressecção cirúrgica total do tumor, porém as reincidências de tumores variam entre 5 e $20 \%$. Consequentemente, a citometria de fluxo mediante a identificação de marcadores biológicos, preferencialmente para a avaliação da atividade proliferativa do tumor é de grande relevância e tem implicações significativas nos prognóstico e tratamento de meningiomas cerebrais (LIN et al., 2015).

Devido à importância dos estudos dos mecanismos moleculares que regulam as células tumorais, novas técnicas envolvendo a FC têm sido desenvolvidas. Recentemente, foi desenvolvida uma técnica para produzir sondas fluorescentes de RNA para identificar moléculas de RNAm expressas em células vivas. Suspensões de células de diferentes tipos de tumores foram submetidas à FC após adicionadas sondas fluorescentes específicas para moléculas de RNAm de células tronco desses tumores. Foi possível identificar e isolar células tronco tumorais, que posteriormente se mostraram viáveis. Essa técnica é o aumento do leque de opções em pesquisa de tumores ao permitir a marcação de RNA das células tronco malignas, facilitando sua identificação e pesquisa para descoberta de marcadores e novas opções terapêuticas (McCLELLAN et al., 2015).

\section{CONCLUSÕES}

Desde os primórdios da espécie, o Homo sapiens tem se caracterizado pela curiosidade em relação ao ambiente que o cerca e a si mesmo. A primeira civilização humana que floresceu na Terra, a egípcia, já se preocupava intensamente em descobrir como era composto e como funcionava o organismo do homem e dos animais, como sugerem os hieróglifos registrados nos papiros e nas ruínas das magníficas construções. Ao longo da história, lentos progressos nesse 
campo do conhecimento foram feitos até o advento do microscópio por Leeuwenhoek que resultou na descrição da célula por Hooke. A partir de então, as descobertas sobre as células e seus mecanismos biológicos se acumularam acentuadamente, adquirindo um ritmo vertiginoso a partir da segunda metade do século $X X$.

Nesse contexto, a citometria de fluxo foi desenvolvida como um instrumento poderoso para a descoberta dos fenômenos celulares. Essa tecnologia, ao fornecer a quantificação precisa de parâmetros celulares físicos (tamanho e granulometria) e químicos (quantidade de proteína expressa, por exemplo), permite que células de interesse sejam descobertas ou testadas diante de diversas situações de pesquisa. Pode ser destacada, a título de ilustração de sua importância, a detecção de subpopulações de linfócitos em pacientes vítimas da síndrome da imunodeficiência adquirida (AIDS), parâmetro essencial para acessar a condição clínica e definir tratamentos mais específicos para cada doente.

Um dos dilemas mais cruciais da pesquisa na área biológica é determinar os mecanismos envolvidos nas respostas celulares a estímulos externos, benéficos ou não. Se em sua fase primordial os cientistas se esmeravam em observar os fenômenos, o grande desafio que se tem atualmente é explicar e interferir nesses fenômenos, principalmente com finalidade terapêutica. Assim, as técnicas de cultivo celular e citometria de fluxo são poderosas aliadas ao possibilitar ao pesquisador reproduzir o fenômeno observado em condições controladas e identificar vias de transdução de sinal intracelulares envolvidas.

A medicina veterinária pode se beneficiar de forma acentuada da utilização de citômetros de fluxo na pesquisa e mesmo na prática clínica. Difundir a importância e desmistificar a utilização dos citômetros contribuirá sobremaneira com o refinamento, acurácia e repetibilidade das técnicas e da qualificação de resultados experimentais e de algumas condutas clínicas por parte do profissional veterinário.

\section{REFERÊNCIAS}

ALTMAN, M. Hoje na História: 1723 - Morre o microbiologista Anton van Leeuwenhoek. In: Opera Mundi, São Paulo, aug 2012. Disponível em: $<$ http://operamundi.uol.com.br/conteudo/historia/23918/hoje+na+historia+1723++morre+0+microbiologista+anton+van+leeuwenhoek+.shtml>. Acesso em: 4 out. 2015.

AMBRIZ-AVIÑA, V.; CONTRERAS-GARDUÑO, J. A.; PEDRAZA-REYES, M. Applications of flow cytometry to characterize bacterial physiological responses. BioMed Research International, p. 1-14, 2014. Disponível em: <http://www.ncbi.nlm.nih.gov/pubmed/25276788>. doi: 10.1155/2014/461941

BACHER P, SCHEFFOLD A. Flow-cytometric analysis of rare antigen-specific T cells. Cytometry Part A, v. 83, n. 8, p. 692-701, 2013. Disponível em: <http://www.ncbi.nlm.nih.gov/pubmed/23788442>. doi: 10.1002/cyto.a.22317

BENDALL, S. C.; NOLAN, G. P.; ROEDERER, M.; CHATTOPADHYAY, P. K. A deep profiler's guide to cytometry. Trends in Immunology, v. 33, n. 7, p. 323-332, 2012. Disponível em: <http://www.ncbi.nlm.nih.gov/pmc/articles/PMC3383392/>. doi: 10.1016/j.it.2012.02.010 
BERTHO, A. L. In: Apostila de Citometria de fluxo. Disponível em: <http://picf.ioc.fiocruz.br/apostila.doc.>. Acesso em: 21 set. 2015.

BROWN, L.; GREEN, C. L.; JONES, N.; STEWART, J. J.; FRASER, S.; HOWELL, K.; XU, Y.; HILL, C. G.; WIWI, C. A.; WHITE, W. I.; O'BRIEN, P. J.; LITWIN, V. Recommendations for the evaluation of specimen stability for flow cytometric testing during drug development. Journal of Immunological Methods, v.418, p.1-8, 2015. Disponível em: <http://www.ncbi.nlm.nih.gov/pubmed/25662815>. doi: 10.1016/j.jim.2015.01.008

DU, L.; GROVER, A.; RAMANAN, S.; LITWIN, V. The evolution of guidelines for the validation of flow cytometric methods. International Journal of Laboratory Hematology, v. 37, p. 3-10, 2015. Disponível em: <http://www.ncbi.nlm.nih.gov/pubmed/25976954>. doi: 10.1111/ijlh.12344

FANG, Y.; RAMASAMY, R. P. Current and Prospective Methods for Plant Disease Detection. Biosensors, v. 4, p. 537-561, 2015. Disponível em: <http://www.mdpi.com/2079-6374/5/3/537>. doi:10.3390/bios5030537

FERRAZ, R. Citometria de Fluxo Cell Shorting: fundamentos e aplicações; Disponível em: <http:/picf.ioc.fiocruz.br/Apostila\%20de\%20Citometria\%20de\%20Fluxo\%20\%20sorti ng.pdf> Acesso em: 21 set. 2015.

GREEN, R.; WACHSMANN-HOGIU, S. Development, History, and Future of Automated Cell Counters. Clinics in Laboratory Medicine, v.35, p.1-10, 2015. Disponível em: <http://www.ncbi.nlm.nih.gov/pubmed/25676368>. doi: 10.1016/j.cll.2014.11.003

HARRISON, P.; LORDKIPANIDZE, M. Testing platelet function. Hematology/Oncology Clinics of North America, v. 27, p. 411-441, 2013. Disponível <http://www.sciencedirect.com/science/article/pii/S0889858813000208>. doi:10.1016/j.hoc.2013.03.003

HERDERSCHEE, J.; FENWICK, C.; PANTALEO, G.; ROGER, T.; CALANDRA, T. Emerging single-cell technologies in immunology. Journal of Leukocyte Biology, $v$. 98, p. 23-32, 2015. Disponível em: http://www.ncbi.nlm.nih.gov/pubmed/25908734 doi: 10.1189/jlb.6RU0115-020R.

ISRAEL, J. S. Laboratory testing for platelet function disorders. International Journal of Laboratory Hematology, v. 37, p. 18-24, 2015. Disponível em: <http://onlinelibrary.wiley.com/doi/10.1111/ijlh.12346/pdf>. doi:10.1111/ijlh.12346

JAHAN-TIGH, R. R.; RYAN, C.; OBERMOSER, G.; SCHWARZENBERGER, K. Flow Cytometry. Journal of Investigative Dermatology, v. 1, p. 132, 2012. Disponível em: <http://www.ncbi.nlm.nih.gov/pubmed/22971922>. doi:10.1038/jid.2012.282

LIN, Y. W.; TAI, S. H.; HUANG, Y. H.; CHANG, C. C.; JUAN, W. S.; CHAO, L. C.; WEN, M. J.; HUNG, Y. C.; LEE, E. J. The application of flow cytometry for evaluating biological aggressiveness of intracranial meningiomas. Cytometry Part B: Clinical 
Cytometry, v. 88, n. 5, p. 312-319, 2015. Disponível em: http://www.ncbi.nlm.nih.gov/pubmed/25408130. doi: 10.1002/cyto.b.21202

McCLELLAN, S.; SLAMECKA, J.; HOWZE, P.; THOMPSON, L.; FINAN, M.; ROCCONI, R.; OWEN, L. mRNA detection in living cells: a next generation cancer stem cell identification technique. Methods, v. 82, p. 47-54, 2015. Disponível em: http://www.ncbi.nlm.nih.gov/pubmed/25920950. doi: 10.1016/j.ymeth.2015.04.022

MAGUIRE, O.; TARIO, J. D. J. R.; SHANAHAN, T. C.; WALLACE, P. K.; MINDERMAN, H. Flow cytometry and solid organ transplantation: a perfect match. Immunol Investigations, v. 43, n. 8, p. 756-74, 2014. Disponível em: <http://www.ncbi.nlm.nih.gov/pubmed/25296232>. doi: 10.3109/08820139.2014.910022

MANCEUR, A. P.; KAMEN, A. A. Critical review of current and emerging quantification methods for the development of influenza vaccine candidates. Vaccine, $\quad$ v. 15, p. 1108-1, 2015. Disponível em: <http://www.ncbi.nlm.nih.gov/pubmed/26271833>. doi: 10.1016/j.vaccine.2015.07.104

MURMANN, J. P. Knowledge and Competitive Advantage in the Synthetic Dye Industry, 1850-1914: The coevolution of firms, technology, and national institutions in Great Britain, Germany, and the United States. New York: Cambridge University Press, p. 763-988, 2007. Disponível em: < http://www.jstor.org/stable/23699532>. doi: 10.1093/es/1.4.699

O'DONNELL, E. A.; ERNST, D. N.; HINGORANI, R. Multiparameter flow cytometry: advances in high resolution analysis. Immune Network Research, v. 13, n. 2, p. 4354, 2013. Disponível em: <http://www.ncbi.nlm.nih.gov/pmc/articles/PMC3659255/>. doi: 10.4110/in.2013.13.2.43

POSTERARO, B.; SANGUINETTI, M. The future of fungal susceptibility testing. Future Microbiology, v. 9, n.8, p. 947-67, 2014. Disponível em: <http://www.ncbi.nlm.nih.gov/pubmed/25302953>. doi: 10.2217/fmb.14.55

RAHMAN, M. In: Introduction to flow cytometry, (USA). Disponível em: $<$ https://www.abdserotec.com/static/Lit-pdfs/Brochures1/flowcytometry.pdf>. Acesso em: 12 out. 2015.

ROSE, J. A.; ERZURUM, S.; ASOSINGH, K.; Biology and flow cytometry of proangiogenic hematopoietic progenitors cells. Cytometry Part A, v. 87, n. 1, p. 519, 2015. Disponível em: <http://www.ncbi.nlm.nih.gov/pubmed/25418030>. doi: 10.1002/cyto.a.22596

TELFORD, W. G. Near infrared lasers in flow cytometry. Elsevier Academic Press Inc, v.82, n.12-20, 2015. Disponível em: <http://www.ncbi.nlm.nih.gov/pubmed/25814439>. doi: 10.1016/j.ymeth.2015.03.010

TEVA, A.; FERNANDEZ, J. C. C.; SILVA, V. L. Imunologia. In: MOLINARO, E. M.; CAPUTO, L. F. G.; AMENDOEIRA, M. R. R. (Eds.) Conceitos e Métodos para 
formação de profissionais em laboratórios de saúde. 1 ed. Rio de Janeiro: Instituto Oswaldo Cruz, p.1-124, 2009.

VERSCHOOR, C. P.; LELIC, A.; BRAMSON, J. L.; BOWDISH, D. M. E. An Introduction to Automated Flow Cytometry Gating Tools and Their Implementation. Frontiers in Immunology, v. 27, p. 6-380, 2015. Disponível em: <http://www.ncbi.nlm.nih.gov/pmc/articles/PMC4515551/>. doi: 10.3389/fimmu.2015.00380 